\title{
Leprosy in Guyana, 1990-95: Lepra Elective Study*
}

\author{
HOLLY ALEXANDER $\dagger \&$ RICARDO PERSAUD $\ddagger$ \\ $\dagger$ Guyana Hansen's Disease Control Programme, Brickdam, \\ Georgetown, Guyana; $\$ 50$ Waller Road, Telegraph Hill, London \\ SE14 5LA, UK
}

\section{Introduction}

Guyana lies on the north-east coast of South America and has an area of 83,000 square miles $(215,000 \mathrm{sq} \mathrm{km})$. The population estimate in 1992 was 730,000 and comprised of East Indians (50\%), Blacks (36\%) Indigenous Ameridian (7\%) and 7\% comprising Chinese, Portuguese and mixed-race people. While Guyana is geographically located in South America, it is culturally an integral part of the English-speaking Caribbean and politically and economically a member state of the Caribbean Common Market (CARICOM). For administrative and political reasons the country has been divided into 10 regions (see Figure 1), each providing primary health care services.

The last publication on leprosy in Guyana was in 1989 by Particia Rose ${ }^{1}$ and the aim of this paper is to update the situation. Leprosy in Guyana is monitored by the headquarters of the Guyana Hansen's Disease Control Programme (GHDCP) which is located in Brickdam, Georgetown. The programme started in Guyana with the establishment of the Mahaica Asylum, the first in the world, in 1958 as a refuge for poor leprosy patients. Since 1988, GHDCP has been funded by the Netherlands Leprosy Relief Association (NSL).

In 1971, a programme based entirely on domiciliary care was introduced. It is a vertically structured one functioning as an urban and rural dermatological service. Approximately $86 \%$ of the population of Guyana live in the coastal region and the clinics are located in this coastal strip except for two clinics in the mining town. There is no special clinic for leprosy control other than the headquarters office situated in the capital Georgetown. The GHDCP has embarked on a programme for the integration of leprosy into the primary health care service and leprosy work has been handed over to the various regions, with the officers at the headquarters acting as consultants.

Currently, the GHDCP has a staff complement of 13 who are well equipped to recognize leprosy (4 of the staff receive salary from NSL project funds). Except for the laboratory technician, the high turn over of staff common to other sections of the health sector in Guyana is not true for the leprosy clinic.

* This study was undertaken during an 8-week period as a Lepra Elective Student 


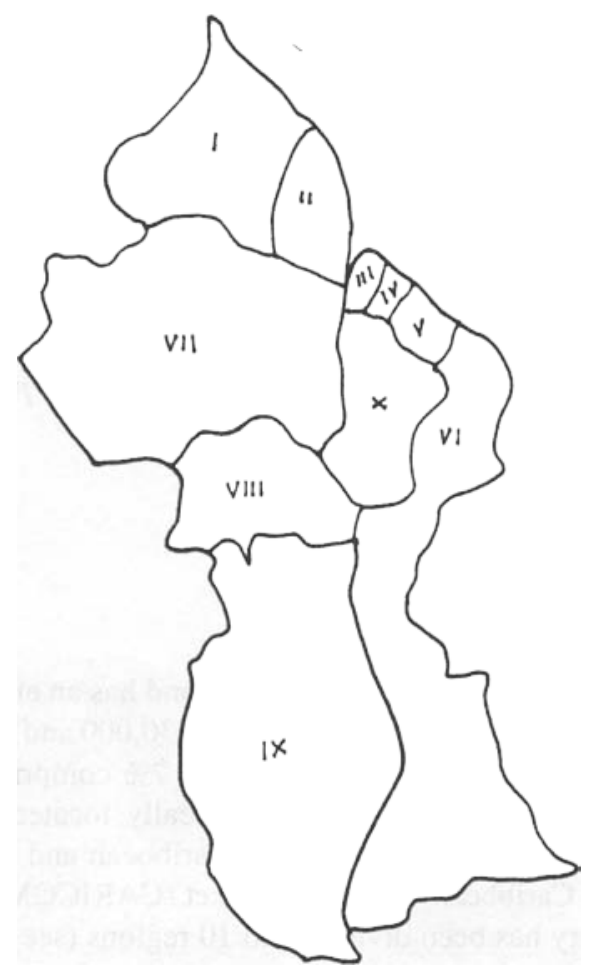

Figure 1. Political-administrative regions of Guyana

Regions
I
II
III
IV
V
VI
VII
VIII
IX
X
Tota

Regional Descriptions

Barima/Waini

Pomeroon

Essequibo/West Demerara

Demerara/Mahaica

Mahaica/Bercice

East Berbice/Corentyne

Cuyuni/Mazaruni

Potaro/Siparuni

Upper Takatu/Upper Essequibo

Upper Demerara/Berbice
Population (1992)

18,590

42,769

91,328

297,162

49,498

142,839

15,342

5,737

15,087

39,106

$717,458 *$

* This excludes the non-household institutional population, floating population (e.g. people without a normal residence) and foreign nationals. The total of these is estimated as 13,000 bringing the total population of the country to about 730,000 .

\section{The leprosy situation in Guyana (1990-95)}

The following tables and text highlight the status of leprosy in Guyana over the last 5 years.

The incidence has been fairly constant over the last 5 years; an average of 34 new patients per year were registered with the number of males being approximately equal to that of females. The 48 patients recorded in 1992 may be a reflection of an increase in case detection activity. The higher percentage of PB cases seems to be consistent with the proposal that with an increasing tendency to eradication, more $\mathrm{PB}$ than $\mathrm{MB}$ cases will be diagnosed. 
Table 1.(a). Epidemiology of leprosy in Guyana, 1990-1995

\begin{tabular}{|c|c|c|c|c|c|c|c|c|c|}
\hline \multirow[b]{2}{*}{ Year } & \multirow[b]{2}{*}{ New cases } & \multirow[b]{2}{*}{$\%$ Male } & \multirow[b]{2}{*}{$\%$ Female } & \multirow{2}{*}{$\begin{array}{c}\text { \%Children } \\
\qquad(0-14)\end{array}$} & \multicolumn{3}{|c|}{ Race } & \multirow[b]{2}{*}{$\% \mathrm{MB}$} & \multirow[b]{2}{*}{$\%$ PB } \\
\hline & & & & & $\% \mathrm{~B}$ & $\% \mathrm{I}$ & $\% \mathrm{M}$ & & \\
\hline 1990 & 34 & 62 & 38 & 29 & 47 & 44 & 9 & 38 & 62 \\
\hline 1991 & 36 & 47 & 53 & 27 & 58 & 33 & 9 & 22 & 78 \\
\hline 1992 & 48 & 58 & 42 & 31 & 35 & 52 & 13 & 27 & 73 \\
\hline 1993 & 23 & 30 & 30 & 30 & 43 & 35 & 22 & 39 & 61 \\
\hline 1994 & 27 & 48 & 52 & 15 & 41 & 48 & 11 & 48 & 52 \\
\hline 1995* & 19 & 58 & 42 & 10 & 26 & 53 & 21 & 26 & 74 \\
\hline
\end{tabular}

* Jan-Sept data only.

B, black; I, East Indian; M, mixed.

MB, multibacillary; PB, paucibacillary.

Data from private hospitals and private doctors is not known.

Table 1(b). Incidence of leprosy per 10,000

\begin{tabular}{lcccccc}
\hline & & & & & \\
Year & 1990 & 1991 & 1992 & 1993 & 1994 & 1995 \\
Incidence* & 0.4 & 0.5 & 0.6 & 0.3 & 0.4 & 0.3 \\
\hline
\end{tabular}

Table 1(c). Prevalence of leprosy per 10,000

\begin{tabular}{lccccc}
\hline & & & & & \\
Year & 1990 & 1991 & 1992 & 1993 & 1994 \\
Prevalence $\dagger$ & 0.11 & 0.6 & 0.4 & 0.5 & 0.6 \\
\hline
\end{tabular}

†The prevalence can be defined as the number of individuals with the disease in a specific time, e.g. 1 year, divided by the population at risk.

The year 1994 was better for children than the previous years as only $15 \%$ of the newlydiagnosed patients were under 14, but it is worrying that there is still active transmission in the communities. With malnutrition and poor social condition prevailing among various areas, it is imperative to have total eradication of leprosy.

The data suggest that Black and Indian people are affected equally, and generally these two races appear to be affected more than Mixed race people. These findings may reflex the proportion of the various races in the population but one needs to remember that the data from private hospitals and private doctors are not known.

All patients registered are placed on the standard WHO-MDT regimens: dapsone and rifampicin for $\mathrm{PB}$ and dapsone, rifampicin and clofazimine for $\mathrm{MB}$. These have been found to be convenient to the patients and health workers. If patients do not report for treatment, it is

Table 2. Registered number of cases on chemotherapy

\begin{tabular}{lccccc}
\hline & & & & & \\
Years & 1990 & 1991 & 1992 & 1993 & 1994 \\
Cases & 84 & 42 & 30 & 38 & 43 \\
\hline
\end{tabular}


Table 3. Registered number of cases on surveillance

\begin{tabular}{lccccc}
\hline & & & & & \\
Year & 1990 & 1991 & 1992 & 1993 & 1994 \\
Cases & 222 & 165 & 169 & 155 & 144 \\
\hline
\end{tabular}

promptly taken to their homes or workplace. This system has resulted in the situation that many patients, especially those on long duration treatment, received their drugs at home and find it convenient not to visit the clinic.

Since the introduction of MDT in December 1981, the number of patients registered for treatment has decreased considerably. This has been mainly due to the short duration of treatment required for PB cases. Eight percent of patients on treatment live in Regions III and IV, i.e. in the vicinity of Georgetown, where patients with a dermatological (or leprosy) problem would normally attend the special dermatological service either at the Georgetown Hospital or at the Public Health Clinic.

The apparent steep fall of cases in 1991 has been as a result of 42 patients being released from extended treatment. The trend in the Guyana Hansen's Disease Control Programme was to continue to treat patients at least one year after their smears were negative or at least one year after prednisolone therapy was terminated. This was changed in September 1991, in keeping with the recommendations of ILEP (24 monthly doses of MDT for MB patients) and now PB is treated for 6 months and MB for 24 months. An average of 38 patients are now on chemotherapy each year and in 1994 Guyana records a 100\% PB compliance and a 95-98\% MB compliance so that almost all patients complete their regime within the specified time. The figure for the average number of patients is considered to be small and this resulted in a smaller workload and better manageability.

Patients released from treatment are placed on passive surveillance, 3 years for PB and 5 years for MB.

The surveillance figures are high in ratio to the staff complement of 13 . Consequently, a system of passive surveillance was introduced and the staff lost contact with many of the patients. The strategy now is to update regularly the contact examination cards and use the opportunity to remind patients about the surveillance visits.

In 1993 five relapsed cases were recorded of which four were MB. The single PB had not been regular while on treatment. Interestingly there was no relapse when the one extra year regime was used. It is unfortunate that facilities are not available to have patients investigated as to the cause of the relapse or whether it was a re-infection.

There are now 21 residents at the Mahaica Leprosarium which is run by the Ministry of Labour and Social Services and is visited monthly by the medical of ficer from the Public Health Clinic. Social Impact Amelioration Programme (SIMAP) provides food for about 50 home-based former patients as well as for former residents at the Mahaica Leprosarium.

The "dole" system for a few disabled patients is in place. Some money is available from the Social Welfare Fund to buy commercial shoes for a few patients. The footwear technician

Table 4. Number of cases who relapsed after MDT

\begin{tabular}{lccccc}
\hline Years & 1990 & 1991 & 1992 & 1993 & 1994 \\
Patients & 0 & 0 & 0 & 5 & 1 \\
\hline
\end{tabular}


Table 5. Number of patients in care*

\begin{tabular}{lccccc}
\hline & & & & & \\
Year & 1990 & 1991 & 1992 & 1993 & 1994 \\
Patients & 56 & 56 & 72 & 70 & 68 \\
\hline
\end{tabular}

* Patients at the Mahaica Leprosarium have been included from 1992.

for the Mahaica Leprosarium died several years ago and since then there has been no provision of special footwear for leprosy patients. Currently, there may be up to 30 patients who desperately require special shoes. There is no footwear workshop in Guyana and no shoemaker from outside the country has yet visited despite numerous correspondences with Trinidad and Tobago.

An ongoing programme of ulcer care including dressing and POP casts/splints is aimed at preventing infections and disabilities.

One disabled girl has had sewing lessons but needs a sewing machine. She and one boy need hand surgery which is not currently available in the Caribbean. The leprosarium is badly in need of a library for its residents.

Most patients are found before developing grade II disability. Denial, hiding and ignorance are some of the reasons for the high proportion of disability reported in 1993. This indicates that there is still a need for education about leprosy. It has been reported that general practitioners have misdiagnosed obvious leprosy and with time the result was deformity for the patient; at least two patients had been seeing a doctor for at least three years and treated for arthritis.

About $70 \%$ of the new cases are detected through self-referral or referral from other health personnel. Area and school surveys are only carried out upon indication. For instance, following the detection of a few new patients from Fort Island in the Essequibo River, a survey of the remaining 90 inhabitants was carried out and one further new case was identified.

Generally, the programme achievement regarding case-finding has been satisfactory. More than $90 \%$ of the cases are detected before disabilities have occurred. However, some cases could be detected earlier if contact examinations are done systematically.

\section{Integration}

The programme aims to achieve complete integration of all leprosy control activities into the

Table 6. Registered new cases and proportion of Grade II disability

\begin{tabular}{lcc}
\hline Year & New cases & Grade II disability (\%) \\
\hline 1990 & 34 & 6 \\
1991 & 36 & 6 \\
1992 & 48 & 0 \\
1993 & 23 & 26 \\
1994 & 27 & 0 \\
$1995^{*}$ & 19 & 10 \\
\hline
\end{tabular}

* Jan-Sept data only. 
Table 7. Methods of detection (expressed as a percentage)

\begin{tabular}{|c|c|c|c|c|c|c|}
\hline & 1990 & 1991 & 1992 & 1993 & 1994 & 1995 \\
\hline Self referral & 31 & 36 & 42 & 48 & 48 & 26 \\
\hline Contact examination & 26 & 6 & 8 & 17 & 11 & 37 \\
\hline Gen health staff & 41 & 39 & 27 & 22 & 18 & 16 \\
\hline GHDCP staff & 6 & 3 & 10 & 0 & 15 & 11 \\
\hline Areas/school surveys & 0 & 9 & 11 & 0 & 4 & 5 \\
\hline General public & 6 & 8 & 2 & 13 & 4 & 5 \\
\hline
\end{tabular}

* Jan-Sept data only.

general health services of Regions II, III, IV, VI and X by the end of 1997. The pilot project in Region II (Pomeroon) was completed in 1993 and considered to be successful. Planned activities for integration in Region III and VI were carried out in 1995. Regions IV and X integration will be carried out in 1996 and 1997. There are no routine dermatology/leprosy clinics run by the leprosy staff from the Public Health Clinic in Region II. In Region III, there are three regular dermatology/leprosy clinics being held and, despite the training exercise, the 11 registered patients are still managed by the specialist visiting staff. There will continue to be regular dermatology/leprosy clinics in Region IV (Georgetown) VI and $\mathrm{X}$ and the leprosy clinic staff will probably, therefore, continue to manage the patients in these regions. Complete integration is unlikely to be achieved but awareness amongst health workers has been raised.

\section{Laboratory services}

The leprosy workload in the laboratory is small (130 skin smears were examined in 1994) and the laboratory facilities at the leprosy clinic are reasonably adequate. It may be worth discussing its possible extension to other activities, such as sputum examination. At the same time the number of routine repeat smears can be reduced, in line with the guidelines in the WHO publication. " "A guide to eliminating leprosy as a public health problem" (WHO/ LEP/95.1, Geneva, First edition 1995). (Currently, it is routine GHDCP practice for PB patients on 6 months of chemotherapy to have a skin smear at the start, at the end and yearly for the 3 years of surveillance. For MB patients the practice is for an annual smear to be taken during treatment and until the completion of 5 years of surveillance.)

The programme has suffered from a frequent change of laboratory technicians. The previous technician was accepted for entry to the medical school and a replacement technician was eventually posted and trained by the project leader. The technician normally goes on the supervision visits and takes smears as well as assisting in patient management. However, the new technician has also been recently selected for entry to the medical school. At one of the author's time of leaving a replacement technician had not been found.

NB Biopsies are not read in Guyana; the samples are sent to the Caribbean Research Council (CAREC) in Trinidad. 


\section{Training and health education}

All nursing students and interns from the medical school get 2-week exposure in the leprosy clinic so that they can function in the community. Lectures are given to doctors at general medical association meetings. Patients are asked about the doctors they visited before being diagnosed and those doctors are visited and given information about the disease so that they do not misdiagnose leprosy.

There has been considerable health promotion work about leprosy. A booklet has been produced in addition to handouts, posters and stickers. Photocopies of extracts from Partners are occasionally used. It is proposed that a short video clip from Trinidad be shown on local television and there have been discussions regarding a locally made documentary film. Teaching about leprosy in schools is undertaken by GHDCP staff.

\section{Conclusions}

We are happy to conclude that the leprosy in Guyana is well controlled and managed and that the GHDCP is well supported and functioning efficiently.

\section{Acknowledgments}

This work was supported by the Netherlands Leprosy Relief Association (NSL), Lepra Medical Elective Award and St Francis Leprosy Elective Award.

\section{References}

${ }^{1}$ Rose, P. Changes in epidemiological indices following the introduction of WHO-MDT into the Guyana leprosy control programme. Lepr Rev 1987; 60: 515-56.

2 WHO. A guide to eliminating leprosy as a public health problem. WHO/LEP/95.1, WHO, Geneva, Switzerland. 